\title{
THERE WAS SOMETHING MISSING
}

\author{
A CASE STUDY OF A FACULTY MEMBER'S SOCIAL \\ INTELLIGENCE DEVELOPMENT
}

Tamara Rosier, Grand Valley State University

Some faculty members seem to lack the social intelligence or relational skills needed to successfully "read" and respond to their students. This chapter describes the process of developing social intelligence skills in one faculty member. During a series of ten coaching sessions, there was demonstrable change in the faculty member's behavior and a self-reported increase in his social intelligence skills. The findings of this exploratory study suggest that social intelligence can be developed, and it has the potential to have a positive effect on teaching practices and faculty success.

John, a faculty member in a science department, is intelligent and articulate. He spends a great deal of time crafting tests and lectures for his students and wants his students to fully grasp the details of his field. John was referred to me by an administrator because of the high withdrawal rate from his courses, numerous student complaints, below-average student evaluations, and a very low student grade point average.

For years I met with faculty members who were not successful in the classroom, coaching them to use more appropriate pedagogical strategies. Yet in spite of using good theory-driven practices, a few professors still experienced a significant disconnect in their classroom. I was missing something. Teaching is a multifaceted, complex process and involves far more than merely conveying information. Research has demonstrated that successful teachers "read" their students' nonverbal signals, discern how their students might be feeling, manage the affective elements in a class, understand how to influence the behaviors of their students, and 
show appropriate concern (Hall, Rosenthal, Archer, DiMatteo, \& Rogers, 1977; Wilmington, 1992). Some faculty members, however, seem to lack the relational skills needed to read and respond to their students. In these cases, better teaching strategies alone are not enough.

\section{Social Intelligence Theory}

The notion of social intelligence was originally put forth by Thorndike (1920) as "the ability to understand and manage men and women, boys and girls, to act wisely in human relations" (p. 228). A person who is socially intelligent understands what another person is feeling and is able to act effectively and appropriately based on that understanding. While some researchers (Eisner, 1986) have restricted the definition to deal only with knowledge of social situations, others agree that social and emotional intelligence overlap (Kang, Day, \& Meara, 2005; Mayer, Salovey, \& Caruso, 2000; Salovey \& Mayer, 1990). However, social intelligence is differentiated from other intelligences by its focus on others (Weis \& Süb, 2007).

The key elements of many social intelligence models include social understanding and the ability to respond appropriately. Weis and Süb (2007) have created a social performance model that includes understanding, memory, perception, creativity, and knowledge. Cantor and Kihlstrom (1986) have outlined the kinds of concepts people use to make sense of their social relations, the rules they use to draw inferences, and their rules for planning actions. Albrecht (2005) has proposed a five-part model of social intelligence: situational awareness, presence, authenticity, clarity, and empathy.

The conceptual framework for this case study is the social intelligence paradigm put forth by Goleman (2006). Drawing on concepts from neuroscience and psychology, Goleman presents a model of social intelligence that includes the synergistic interplay of brain and biology. He explains that our brain physiology is shaped by our social interactions. He describes the difference between two brain processes: "high road" and "low road." The high road uses a comparatively slow neurological pathway when we analyze and consciously think. High-road thinking runs through neural systems that work methodically with deliberate effort. Low-road thinking is instinctive and provides us with intuitive feelings (LeDoux, 1998; Gallese, 2007). Low-road operations in the amygdala are emotionally based; they allow us to walk into a room and sense a silent disagreement. According to Goleman, social intelligence is the ability to effectively use both low-road and high-road processes. Goleman's model of social intelligence is descriptive, not definitive. In his model, social intelligence is organized into two broad categories: social awareness and social faculty. 


\section{Social Awareness}

Goleman's (2006) first category of social intelligence, social awareness, encompasses primal empathy, attunement, empathetic accuracy, and social cognition. All of these skills are important to effective teaching and can be developed to improve faculty-student relationships:

- Primal empathy is the ability to sense and make meaning of another's nonverbal emotional signals, communicated unconsciously through facial muscles (Ekman, 2007). Faculty members who do this well can spontaneously read nonverbal clues and are viewed as more effective by their students (Hall et al., 1977).

- Attunement refers to the ability to listen with full receptivity. When faculty members focus attention on the individual speaking, they are making an effort to connect on a personal level by listening intentionally.

- Empathetic accuracy has to do with understanding another person's thoughts, feelings, and intentions. Research performed in the area of empathetic accuracy suggests that our readings of the thoughts and feelings of others can be accurate (Ickes, 2001). Faculty members who do this well remember what it was like to be a student, can accurately project how their students may be feeling, and can relate to their students' goals.

- Social cognition is an understanding of the norms and mores of a changing environment. Faculty members who do this well can read the politics of a classroom. They can accurately interpret the social currents to see which students will influence other students, how some behaviors affect the entire class, and how their presence affects class interactions.

\section{Social Faculty}

Goleman's (2006) second category of social intelligence, social faculty, encompasses synchrony, self-presentation, influence, and concern. Development of these skills is important to faculty interactions with students:

- Synchrony refers to individuals' interacting smoothly at the nonverbal level. Since much of our communication is nonverbal (Mehrabian, 1981), we perform a mostly unconscious social dance that causes individuals to react to social cues without thinking about it. Faculty who do this well interact smoothly and effectively with their classes.

- Self-presentation is the ability to present oneself effectively. Professors who do this well convey a confident, calm, knowledgeable, and caring 
persona to the class. They effectively convey behavioral expectations to their class without words because they have convinced their students that they are leading the class.

- Influence is the understanding of and ability to shape the outcome of social interactions. A colleague once stated that he was able to convince his students that completing the final class assignment would help them in their future teaching careers. He understood his influence and its effect on his students. Therefore, he was able to motivate them to invest considerable time and effort in the assignment.

- Concern extends the idea of empathy by adding action and caring about others' needs and then behaving accordingly. Busy schedules threaten this aspect of social intelligence, as seen in the classic Darley and Batson (1973) experiment with seminary students who believed they were late to give a talk about the parable of the Good Samaritan. Subjects in a hurry were far less likely to stop and provide assistance to an actor playing the role of a groaning man who was apparently in distress. Effective teaching faculty. manage their numerous professional tasks while focusing on their students' needs, acting in ways that address students' needs.

\section{Method}

An exploratory case study approach was chosen to observe what happened when a professor who did not seem to have a relational connection to his students was coached in the use of social intelligence. In this case study, Goleman's (2006) social intelligence framework guided the work with the participant. Three research questions were investigated:

1. What areas of social intelligence can be developed in ten coaching sessions?

2. How does the faculty member describe his own perceptions of social intelligence?

3. How does the faculty member understand the impact of social intelligence on his classroom?

\section{Participant}

The case study focused on a single participant-a male science professor with several years of teaching experience, identified here as John. He was an ideal candidate for three reasons: he needed to develop social intelligence, he 
had a desire to learn a new approach, and he seemed to genuinely care for his students.

I am a full-time faculty development professional and was the researcher. I recognized from the beginning that a case study with one participant would generate empirical findings specific only to that case. However, it could contribute to faculty developers' understanding of how to coach colleagues who lack interpersonal connection with their students.

\section{Data Collection}

John and I had ten meetings, lasting from 60 to 150 minutes each. During each meeting, a problem was defined and planned interventions discussed. After John implemented these plans, subsequent meetings evaluated the interventions and defined another problem. I analyzed my notes from each session and e-mail messages between John and me for signs of progress.

I also collected data from reports, other e-mail messages, and student evaluations of teaching, which helped set the baseline of behavior and goals for improvement. Due to confidentiality assurances, it was not possible to validate my observations by triangulating .with other observers. However, John's midterm teaching evaluation provided some cross-checking. I also relied on his self-reflective comments to provide substantiation.

\section{The Initial Meeting}

The goals of the initial meeting were to establish a relationship and assess if John needed improvement in the area of social intelligence. I developed rapport with him by accessing my own social intelligence skills, carefully listening to his story, responding empathetically, and showing concern.

In this first conversation, John explained that he was very irritated with the student behavior that he saw in his classes. He described his students as "lacking of character"; they worked only for a grade and appeared lazy. He had developed a distanced relationship with his students by categorizing them as very different from himself. Although John was frustrated, he wanted to do something about the student behavior.

When I asked him if he liked his students, he responded emphatically that he did care for his students as both individuals and learners. At that point, I had two observations that began to shape my understanding about this case. Although John appeared to genuinely care for his students, 
he seemed disconnected from them. He also perceived this gap and stated that this was not how he wanted to be viewed by them.

As a result of our first meeting, we agreed to work on how he understood his students (primal empathy, empathetic accuracy, and concern), how he could communicate empathetically with his students (influence, concern, and self-presentation), and how he could act in a way that would alter his students' perceptions (concern and self-presentation).

\section{Coaching Sessions}

The topics of the ten coaching sessions followed this general progression:

- Acknowledgment of who John's students were

- Analysis of how his behavior affected students

- Identification of teaching behaviors that were likely to have a positive effect on student learning

- Exploration of John's personal vision of who he wanted to be as a professor

- Introduction of social intelligence

- Discussion of nonverbal behaviors that communicated social intelligence

- Discussion of verbal communication behaviors that communicated social intelligence

- Reflection on John's learning

\section{Primal Empathy, Empathetic Accuracy, and Concern}

In discussing the results of this case study, I am grouping the subcategories primal empathy, empathetic accuracy, and concern together because simultaneous growth occurred in these areas. Each of these subcategories built on one another as John examined his approach to teaching and our first goal of understanding his students. We worked first on empathetic accuracy (the ability to accurately understand how another is feeling) and then on primal empathy (the ability to read another's thoughts or feelings). Concern (acting with the understanding gained from primal empathy and empathetic accuracy) developed as John responded to his students.

At the beginning of the coaching process he asked, "I know what empathy is, but what does it look like in a class?" By the end of our work 
together, he was responding to class situations with increased empathy. He had discovered what empathy in the classroom looked like; practiced understanding another person's thoughts, feelings, and intentions; and demonstrated caring for his students' needs and acting accordingly. He had developed primal empathy by beginning to see student distress, empathetic accuracy when considering how his students felt, and concern when acting on his observations.

\section{STEPS TOWARD EMPATHY}

In the third meeting, John acknowledged that his frustration with students was counterproductive and that it was not helping him solve his problem. In an effort to build a better understanding of his students, develop his empathetic accuracy, and deconstruct some labels that kept him at a distance from his students, we discussed his recent readings on the millennial generation. John analyzed his own beliefs from a generational perspective and contrasted his sense of responsibility to work and learn with that of his students. We discussed the needs of students in his classes. After a few meetings, John could explain that his students were concerned about their ability to pass his difficult required course.

Showing empathy became the topic of discussion at many of our meetings. I insisted that empathy was not merely a "touchy-feely concept to use to make students feel good about themselves," as John once had said, but instead was a significant part of learning. From there we discussed how to show empathy in front of the class and to individuals during office hours.

\section{PRACTICING EMPATHY}

During one meeting, John brought a contentious e-mail message from a student and his response to it. To give him the feedback he wanted, we went over the message like coaches analyzing a football game. He had responded to the student's complaints in a factual tone, carefully addressing each of the student's points. His message was precise, logical, and correct, but there was something missing. I suggested that he could have responded more empathetically and let the student know that he had been heard. I suggested specific phrases that eventually became useful to him, such as, "In your e-mail, you seemed very upset" and "From your e-mail, I can tell that you are frustrated with ..." John took notes and expressed the wish that he had these types of sound bites for other situations. 
In a later meeting, John brought a second student e-mail message to discuss. The student felt that the questions on an exam were unfair and that the answers to the questions contradicted class discussion. The e-mail ended with the student expressing his frustration that all of his studying was not "paying off." This time, John explained to me, he had begun writing an empathetic answer in response but felt as if he were "pandering, insincere, and condescending." We looked at the student's message and analyzed it for emotion first. John identified the emotions of fear and frustration expressed in the message. Then he went back to his office and sent the following e-mail message to the student:

Your message seems to indicate that you are feeling frustrated and perhaps anxious about successfully completing the course. If this is correct I am sorry to hear this. I would very much like to talk with you about developing strategies to improve the effectiveness of the time you spend studying. If you would like to meet to do this send me an email so we can find a time that will work for both of us. Please be assured that it is never my intent to write questions that are either tricky or misleading, although I do compose questions that I hope will access students' depth of understanding.

The first e-mail message John had sent expertly explained why the student's perceptions were incorrect and invalid. This second message illustrated two changes: he addressed the emotions expressed (empathetic accuracy) and invited the student to join a process to improve (concern).

\section{JOHN'S PARADIGM SHIFTS}

By our fifth meeting, John was questioning his assumptions about students and teaching. At one point he explained that they were "all wrong." Although he remained confident in the effectiveness of his teaching methods and wished that students would be responsible and hard working, he recognized that as a professor, he was responsible for motivating students and meeting their needs. He wasn't sure how to do that. When I explained the concept of social intelligence as it relates to empathy and concernand that it could help him understand how to engage students in a new way-he became emotional and said, "I've felt this." At the end of that discussion he said, "I'm missing something." This was an important moment for John: he acknowledged that he lacked social intelligence, specifically in the areas of primal empathy, empathetic accuracy, and concern. 


\section{Self-Presentation}

Self-presentation is the ability to portray ourselves effectively. John had received feedback from his students that they felt "disrespected," that he was arrogant, and that he did not care about their success. John was not presenting himself accurately; that is, he did not want to be viewed that way. We worked on ways to help him present himself as confident and caring.

In the sixth meeting, we discussed the use of midterm teaching evaluations. He noted my suggested language for introducing the idea of a midterm evaluation to students. He wrote in his notebook the specific phrases, "I'm interested in .. .," "Help me understand ...," and "Let's ..." He wanted to be seen as inviting students to join him in a learning process.

\section{MIDTERM EVALUATIONS}

In an effort to improve his self-presentation skills and receive specific student feedback, John decided to conduct midterm evaluations. Because he had never done this before, we discussed the kind of feedback he desired and how to ask questions. The evaluations ultimately provided valuable feedback to him and suggested that he was making progress.

Students were asked to rate their responses to seven prompts on a scale of $\mathrm{A}$ to $\mathrm{E}$ ( $\mathrm{A}=$ totally agree, $\mathrm{C}=$ generally agree, $\mathrm{E}=$ totally disagree), with an area for comments beneath each prompt. One question, "I believe I am free to talk with my professor about my progress in the course if I desire," provided surprising feedback. The answers to this question revealed that he had made progress in portraying himself as someone who could be approached. His upper-level course responded with 90 percent indicating "generally agree" to "totally agree." The majority of the introductory classes (73 percent), his most challenging and critical group, responded with "generally agree" to "totally agree." Some comments from the introductory-level classes showed that he still had some work to do with some students. For example, one student wrote that she agreed she was able to talk with him about her progress, but that it was sometimes "nerve wrecking [sic]" to approach him.

What John did with this feedback was impressive, and it showed his commitment to the process as well as his growing awareness of self-presentation. After carefully reading and reflecting on the midterm evaluations and preparing and rehearsing a response, he talked with his students. He described the theme of fear and anxiety about successfully completing the course and provided some strategies to help them become more successful. He also 
explained that the majority of the class reported that they found him accessible; he invited those who did not to e-mail him or come to his office. Finally, intentionally ending with this point, he addressed a perception that the class moved too quickly through the material. He explained that there was a great deal of content and that he tried to support their learning by preparatory or subsequent assignments. Speaking to his classes this way not only illustrated empathetic accuracy and concern, but also helped him to present himself effectively and authentically. He was building a relationship with his classes.

\section{CHANGING SELF-PRESENTATION}

In our tenth meeting, John explained how he was more effectively addressing some of the myths perpetuated in his field. In the past, he had explained in detail why textbook authors were incorrect or misguided; this was likely one of the behaviors that led students to think he was arrogant. John changed his self-presentation by making a joke when drawing attention to a common myth.

\section{Social Cognition and Influence}

As John practiced his empathetic and self-presentation skills, he noticed situations in his classroom that needed his attention. He began by analyzing how the social elements in his class worked and how he could shape the outcomes of many social interactions. For example, a pair of students would sigh loudly or exchange eye-rolling looks with one another during his class, especially when he was talking about a test or assignment. Because the behavior was noticeable to the entire class, it affected the tone of the room. When John noticed these subtle behaviors, he realized how distracting it was for others and began to strategize ways to intervene.

In another situation, he described a student who would ask questions that seemed to be "nonthinking" inquiries. Instead of becoming irritated (his previous response) and saying, "I'm not going to answer that question," John decided to open the discussion to the class and say, "So, how do we answer that question?" Students responded by chiming in with appropriate answers. In addition to improving his self-presentation, John demonstrated his social cognition and influence skills when he encouraged the class to respond to their classmate's question. He influenced student behavior by asking the class to cooperate and began to understand that students learn better when they are included in the discussion. 


\section{John's Progress}

In one of my last meetings with John, I encouraged him to continue the progress he was making. He looked at me and said, "I was doing many things right, but there was something missing." John explained his progress in this way. First, he became aware of the affective environment surrounding him. Then he practiced specific skills to match his acquired sensitivity. Next, he reflected on his social interactions. Finally, he accumulated "sound bites" to help in specific situations. After ten coaching sessions, he was feeling more aware and sensitized to his class environment. Although he is still learning what it means to act in socially intelligent ways, John has become aware of the possibilities inherent in this model.

\section{Overall Results of Coaching}

The first research question was, "What areas of social intelligence can be developed in ten coaching sessions?" I found that John demonstrated great progress in six areas of social intelligence: primal empathy, empathetic accuracy, concern, self-presentation, social cognition, and influence.

The second research question was, "How does the faculty member describe his own perceptions of social intelligence?" After ten coaching sessions, John was able to articulate a shift in his perception of students and his approach to building relationships in his classes.

The third research question was, "How does the faculty member understand the impact of social intelligence on his classroom?" John reported that he had become more aware of his students' affective states and understood more clearly how to respond to what he observed. $\mathrm{He}$ also appeared to be more satisfied with what happened in his classes.

\section{Discussion}

This case study affirms the importance of acknowledging and caring for the interpersonal communication skills of faculty members who have been identified as not being successful in the classroom due to an apparent lack of interpersonal skills. It is not a clear, simple process, but it is worth the investment of a faculty developer's time and energy.

What should be done when faculty developers suspect that a professor is unsuccessful in the classroom due to low social intelligence? Goleman's (2006) framework has the potential to help faculty developers identify and understand what may be missing in a faculty member's teaching. 
As faculty developers, trusting our own instincts and monitoring our own social intelligence can be informative. For example, does the conversation with a faculty member seem uneasy? To test our assumptions, faculty developers can ask open-ended questions about teaching and learning. Signs of problems with social intelligence in a faculty member could include egocentrism, blaming students for not succeeding, talking extensively about oneself, awkward discussion patterns, the inability to read another's facial cues, misunderstanding of social patterns, and appearing to lack empathy.

When faculty developers are preparing to help faculty members improve their social intelligence, they need to consider how to build rapport with the individual faculty member, develop a commitment to a process, and coach social intelligence skills.

\section{Building Rapport}

Individuals help other individuals grow through relationship with one another. I understood that I had a tremendous opportunity to influence and shape John's classroom behavior by developing an effective coaching relationship. To develop rapport, I modeled social intelligence by attuning with him, focusing on empathetic accuracy, and showing genuine concern. I employed my interpersonal skills by asking questions, listening well, mirroring John's demeanor, showing understanding, and expressing optimism about his success. Taking the time to establish rapport helped make the coaching process more successful.

\section{Developing a Commitment}

Although John's superiors strongly recommended that he work with me, I needed his commitment to the process (Boyatzis, 2009) without which he would not have invested in improving his social intelligence. I asked him about his goals and convinced him that I wanted to help him achieve them. We became partners in the process of improving his teaching experience.

\section{Coaching Social Intelligence}

I found it useful to begin with social awareness so John could begin to be sensitized to his environment. Empathy skills, attuning skills, and social cognition were the topics of our first several discussions. We discussed the basics of empathy and what it looks like in a classroom: using body 
language, reflecting on the other person's statement or feeling, and validating the other's emotions. We discussed how to attune to students: listening with full receptivity; monitoring his own feelings and responses; and focusing on the whole message, spoken and unspoken. We practiced the skills by talking through scenarios, rehearsing dialogues, and reviewing class events. Doing these activities reinforced the high-road aspect of these skills and encouraged the low-road neural pathways to pay attention to new cues.

I learned that providing individuals with "sound bites" can be useful when developing or reinforcing new behaviors. Basic phrases like, "I would like to understand ..." or, "You feel confused when ..." are useful when learning the basics of showing empathy. Other phrases that helped John were inclusive in their language or engaged students in a partnership: "Let us work this out together" or, "After we talk a little more, perhaps we can come up with some solutions that may help."

\section{Limitations of the Study}

The limitations of this case study point to the need for further research. First, baseline data such as classroom observations and analyses of student evaluations of teaching could have been collected before the coaching sessions began. Without early access to such data, my understanding of John's specific deficiencies in social intelligence was limited.

Second, because this case study was exploratory in nature, only my observations and coaching experience have been discussed. As a result, observations in the case study are limited to one participant in a specific time frame and are restricted to what could be observed during the coaching sessions. Additional research, particularly classroom observation and other student data, is needed to determine if improving a professor's social intelligence affects student learning.

\section{Conclusion}

John is not the only faculty member who is "missing something." Many faculty are missing one or more of the key social intelligence skills that allow other faculty to communicate effectively and smoothly with their classes. Goleman's social intelligence paradigm offers faculty developers a model that can be used as a basis for coaching social and communication skills. John made a great deal of progress toward becoming the professor he would like to be in just ten coaching sessions. By improving his social intelligence, he has overcome a substantial teaching barrier and has improved his chances for professional success. 


\section{REFERENCES}

Albrecht, K. (2005). Social intelligence: The new science of success. San Francisco: Jossey-Bass.

Boyatzis, R. E. (2009). Developing emotional, social, and cognitive intelligence competencies in managers and leaders in educational settings. In M. Hughes, H. L. Thompson, \& J. B. Terrell (Eds.), Handbook for developing emotional and social intelligence (pp. 219-241). San Francisco: Pfeiffer.

Cantor, N., \& Kihlstrom, J. (1986). Personality and social intelligence. Upper Saddle River, NJ: Prentice Hall.

Darley, J. M., \& Batson, C. D. (1973). From Jerusalem to Jericho: A study of situational and dispositional variables in helping behavior. Journal of Personality and Social Psychology, 27, 100-108.

Eisner, E. (1986). Aesthetic modes of knowing: An expansive perspective on intelligence. In Proceedings from the 10th Annual Research Symposium: The World of the Mind. Evanston, IL: Northwestern University.

Ekman, P. (2007). Emotions revealed: Recognizing faces and feelings to improve communication and emotional life. New York: Times Books.

Gallese, V. (2007). Before and below "theory of mind": Embodied simulation and the neural correlates of social cognition. In N. Emery, N. Clayton, \& C. Frith (Eds.), Social intelligence: From brain to culture (pp. 276-279). New York: Oxford University Press.

Goleman, D. (2006). Social intelligence. New York: Bantam Dell.

Hall, J. A., Rosenthal, R., Archer, D., DiMatteo, M. R., \& Rogers, P. L. (1977). Nonverbal skills in the classroom. Theory into Practice, 16(3), 162-166.

Ickes, W. (2001). Measuring empathetic accuracy. In J. A. Hall \& F. J. Bernieri (Eds.), Interpersonal sensitivity: Theory and measurement (pp. 219-241). Mahwah, NJ: Erlbaum.

Kang, S., Day, J. D., \& Meara, N. M. (2005). Social intelligence and emotional intelligence: Starting a conversation about their similarities and differences. In R. Schulze \& R. D. Roberts (Eds.), Emotional intelligence: An international handbook (pp. 91-105). Cambridge, MA: Hogrefe \& Huber.

LeDoux, J. (1998). The emotional brain: The mysterious underpinnings of emotional life. New York: Simon \& Schuster.

Mayer, J. D., Salovey, P., \& Caruso, D. R. (2000). Models of emotional intelligence. In R. J. Sternberg (Ed.), Handbook of intelligence (pp. 396-420). New York: Cambridge University Press.

Mehrabian, A. (1981). Silent messages: Implicit communication of emotions and attitudes (2nd ed.). Belmont, CA: Wadsworth. 
Salovey, P., \& Mayer, J. D. (1990). Emotional intelligence. Imagination, Cognition and Personality, 9, 185-211.

Thorndike, E. L. (1920). Intelligence and its use. Harper's Magazine, 140, 227-235.

Weis, S., \& Süb, H. M. (2007). Reviving the search for social intelligence. Personality and Individual Differences, 42, 3-14.

Wilmington, S. C. (1992). Oral communication skills necessary for successful teaching. Educational Research Quarterly, 16, 5-17. 